\title{
Serviços educativos em bibliotecas públicas
}

\author{
Maria Otília Pereira Lage \& Carla Bandeira
}

\begin{abstract}
Resumo
As Bibliotecas Públicas Portuguesas configuram-se hoje como serviços democráticos culturais e educativos, direcionados aos interesses e necessidades dos seus públicos diversificados que procuram atrair e fidelizar proativamente através de estratégias e técnicas de comunicação, motivação, formação e educação integrando as novas tecnologias de informação. Neste enquadramento têm um papel fulcral os Serviços Educativos que funcionam como mediadores entre a biblioteca e os seus utilizadores. Esta importante valência de educação não formal das bibliotecas agrega um conjunto multifacetado de ações de largo espectro: promoção da leitura e da compreensão leitora, desenvolvimento das literacias, projetos de formação ao longo da vida, atividades de caráter lúdico e pedagógico particularmente direcionadas a crianças e jovens, para além de outras iniciativas integradas e/ou segmentadas, mas sempre programadas e planificadas em função dos públicos-alvo. O presente artigo desenvolve a temática enunciada, e nesse contexto, centra-se na descrição, avaliação e análise do panorama nacional atual dos Serviços educativos nas Bibliotecas Públicas Portuguesas.
\end{abstract}

Palavras-chave:

bibliotecas públicas; serviços educativos; rede de leitura pública; rede nacional de bibliotecas públicas. 


\section{Educational Services in Public Libraries}

Abstract: Portuguese Public Libraries are today configured as cultural and educational services geared to the interests and needs of their diverse audiences, who seek to attract and retain loyalty through strategies and techniques of communication, motivation, training and education integrating new technologies of information and capable of responding to the enormous challenges of the current Information and Knowledge Society. In this context, a major role is played by the Educational Services, which function as cultural mediators between the library and its users. This important valence of non-formal education and training of the Libraries aggregates a multifaceted set of broadspectrum actions: promotion of reading and comprehension skills, literacy development, and lifelong cultural training, ludic and pedagogical nature activities, particularly directed at children and young people, in addition to other integrated and / or segmented initiatives, but always scheduled and planned according to the target audiences. The present article develops the synthetically stated theme, and in this context, focuses on the description, evaluation and analysis of the current national panorama of the Educational Services in the Portuguese Public Libraries.

Keywords: public libraries; educational services; public reading network; national public library network.

\section{Services Éducatifs dans les Bibliothèques Publiques}

Résumé: Les bibliothèques publiques de portugaises mises en place aujourd'hui sous le nom des services démocratiques, culturels et éducatifs, sont orientées vers les intérêts et les besoins de leurs différents publics qui cherchent à attirer et à retenir proactivement à travers les stratégies et techniques de communication, motivation, formation et éducation en intégrant les nouvelles technologies de l'information. Dans ce cadre, les services éducatifs jouent rôle très important, servant de médiateurs entre la bibliothèque et ses utilisateurs. Cette importante valence de l'éducation non formelle des bibliothèques comprend un ensemble multidimensionnel d'actions de large spectre: promotion de la lecture et de la compréhension des lecteurs, développement des littératies, projets de formation tout au long de la vie, développement de l'apprentissage, activités de caractère ludique et pédagogiques particulièrement, destinées aux enfants et aux jeunes, au-delà d'autres initiatives intégrées et/ou ciblées, mais toujours programmées et planifiées en fonction des publics cibles. Cet article développe ce thème énoncé et, dans ce contexte, se centre sur la description, l'évaluation et l'analyse du panorama national actuel des services éducatifs dans les bibliothèques publiques portugaises.

Mots clés: bibliothèques publiques; services éducatifs; réseau de lecture publique; réseau national des bibliothèques publiques.

\section{Servicios Educativos en las Bibliotecas Públicas}

Resumen: Las bibliotecas públicas portuguesas se configuran hoy como los servicios democráticas culturales y educativos dirigidos a los intereses y necesidades de sus diversos públicos, que buscan atraer y retener de forma proactiva a través de estrategias y técnicas de comunicación, la motivación, la formación y la educación integradora de las nuevas tecnologías información y capaz de responder a los enormes retos de la información actual y Sociedad del conocimiento. En este contexto tienen un papel clave los Servicios de Educación que actúan como mediadores culturales entre la biblioteca y sus usuarios. Esta valencia importante de la formación no formale de las Bibliotecas añade un conjunto multifacético de amplio espectro de acción: promoción de la lectura y comprensión de lectura, habilidades de desarrollo de la alfabetización, proyectos de información durante toda la vida, actividades lúdicas y pedagógicas dirigidas especialmente a los niños y jóvenes, así como otras iniciativas integradas y/o segmentados, pero siempre programadas y previstas en las audiencias de la función. En este artículo se desarrolla el tema enunciado sintéticamente, y en este contexto se centra en la descripción, evaluación y análisis del panorama actual nacional de Servicios de Educación en bibliotecas públicas portuguesas.

Palabras Clave: bibliotecas públicas; servicios educativos y bibliotecas; red de lectura pública; red nacional de bibliotecas públicas. 


\section{Introdução}

Instituições como bibliotecas, museus, arquivos, centros culturais e outras entidades de idêntica natureza e missão informativa, são hoje em Portugal marcos de vitalidade e diversidade cultural. Refletem e promovem, simultaneamente, a mudança e o dinamismo que caracterizam as sociedades atuais em expansão.

Nas últimas décadas temos assistido ao aumento generalizado da importância da informação e acessos à mesma, o que por si só não significa que seja equivalente à sua transformação em conhecimento e aprendizagem. Ora, as instituições culturais e educativas evocadas têm também uma missão essencial a desempenhar na construção do conhecimento junto dos que as frequentam (Barriga \& Silva, 2007).

É precisamente nesta interceção entre o lazer e a aprendizagem que se localizam esses espaços educativos privilegiados de relacionamento com os públicos, vertente fulcral da função dos SE, embora - o que é de extrema importância - eles estejam integrados na política geral de fundo das respetivas instituições o que não sucede ainda hoje na generalidade das BPs portuguesas, como nos foi possível verificar.

A justificação para a função educativa destas instituições culturais reside no facto de serem fundadoras de consciências críticas e agentes construtivos de mudança e transformação nos vários campos do conhecimento (Barriga,2007). E nesse contexto, esta autora define mesmo um Plano de Ação Educativa (PAE) para os SE como: "Um documento que esclarece, de forma clara e concisa, as metas, objectivos e estratégias da acção pedagógica, tendo por base a política institucional e a responsabilidade que esta assume perante as comunidades a quem se dirige a oferta programática" (p.43). Os princípios norteadores deste PAE assentam no pressuposto de que a instituição serve a comunidade, sendo uma das suas missões a promoção da aprendizagem e educação não formal ao longo da vida. Daí que os responsáveis pelos SE precisem de conhecer e saber responder a um conjunto de questões tais como: "Que atividades educativas posso oferecer aos públicos de todas as idades? Quais são os públicos-alvos, reais e potenciais? Quais as suas expectativas e necessidades (...)" (Barriga, 2007, p.44)

Muitas destas interrogações só encontram respostas no âmbito de um trabalho coerente e eficaz exigido pelo cumprimento de um plano de ação educativa o qual não pode nem deve ser um fim em si mas um meio para a gestão de excelência dos SE em instituições culturais.

Corroboramos assim a utilidade dessas indagações que traduzimos para o domínio das Bibliotecas ${ }^{1}$ onde são também um facto diário incontestável que só com uma metodologia apropriada e rigorosa pode ser enfrentado de modo a ultrapassar obstáculos. A elaboração das linhas orientadoras de um PAE requer uma análise preliminar da instituição, tendo em conta a missão, serviços que disponibiliza e responsáveis, 
porque o mesmo deve reflectir a instituição e correspondentes interesses, prioridades, organização, estrutura e código de ética.

A este título e no caso concreto das bibliotecas há ainda a considerar a experiência pioneira e bem-sucedida dos SE (Serviços Educativos) dos Museus e o conhecimento prático e teórico dos seus responsáveis. Por exemplo, Graça Filipe, subdiretora do Instituto dos Museus e da Conservação (IMC), enfatizava, em 2011, que o interface de comunicação e aprendizagens dos museus com os públicos não se esgotam na oferta dos SE, pois o trabalho é diário e transversal a toda a equipa. A equipa que contacta com o público e, especificamente, a dos SE deve ser de caráter multidisciplinar, contar com profissionais de várias áreas, que terão mais ou menos destaque de acordo com as linhas programáticas da instituição e sua real inserção com o meio em que está integrada. No entanto é necessário “ (...) normalizar conceitos e trocar experiências/coordenar procedimentos de relação com os públicos; cada museu é uma instituição com dinâmica própria, mas os públicos carecem de uma certa normalização de códigos e de meios de descodificação da informação e da linguagem científica" (2011, p.8).

Em sentido idêntico, também Barriga (2011) no seu texto síntese "Serviços Educativos em Portugal: Ponto da Situação Documento de Recomendações" apresenta um conjunto de requisitos programáticos para a estruturação destes serviços específicos dos espaços culturais e educativos considerados: refletir sobre a missão da política educativa das instituições, de maneira a garantir a gestão da instituição e das equipas de trabalho; determinar prioridades a longo e a médio prazo; garantir que os SE desenvolvem a sua programação em consonância com a programação geral da instituição; inovar os modelos que se revelem desatualizados para as necessidades e expectativas do público; programar no sentido de servir os interesses comuns.

As considerações e recomendações sinalizadas são, a nosso ver e por maioria de razão, válidas para as bibliotecas públicas portuguesas onde se revestem da maior pertinência e atualidade, como procuramos demonstrar.

\section{Emergência e configuração dos Serviços Educativos nas Bibliotecas Públicas Portuguesas}

O "Manifesto da Leitura Pública em Portugal" é o primeiro documento onde foram fixadas as ideias estruturantes para a criação de uma política nacional de leitura pública no nosso país. Ainda não com a designação de SE, mas já alicerçadas na ideia de um serviço comunicante com o exterior, com atividades de animação do livro e da leitura, exposições, sessões de teatro (1983).

No mesmo sentido, mas indo um pouco mais longe, os SE nas BPs começando por assumir como principais missões: atrair, formar e fidelizar público, " (...) têm vindo a assumir, cada vez mais, o papel de interfaces de comunicação com as audiências e 
de lugares privilegiados para a construção de saberes e o estabelecimento de relações duradouras e exigentes".

As instituições culturais, nomeadamente as BPs são fundamentais para a estruturação das identidades das comunidades onde estão implantadas. Apresentandose como marcas de vitalidade e de multiplicidade cultural, "promovem e refletem, simultaneamente, a mudança, o dinamismo e a transformação permanentes que caracterizam as sociedades em crescimento e mutação" (Barriga \& Silva, 2007, p.9).

Com o novo milénio, as BPs defrontaram-se com mais um exigente desafio que, indo além do acesso à informação e à cultura, progressivamente mais democratizado e disseminado graças às novas tecnologias, consiste em saber o que e como fazer com elas. A grande aposta é a transformação da informação em aprendizagem e conhecimento, chegar ao ponto onde a informação se interrelaciona e produz conhecimento (obra citada acima, p.9).

Neste novo contexto as BPs passaram a ter a sua missão educativa muito mais alargada junto de uma maior diversidade de públicos mais exigentes pois recebem nas suas instalações, desde crianças de tenra idade a adolescentes e utilizadores mais idosos e ainda ativos. Assim, diariamente lidam com necessidades variadas, desde o leitor mais jovem que vai requisitar um livro ou um vídeo ao adulto que vai ler um jornal ou uma revista genérica ou especializada, passando pelo estudante de diferentes níveis de ensino que busca informação sobre um determinado tema.

De acordo com o Manifesto da UNESCO sobre Bibliotecas Públicas (1994), estas têm por missão possibilitar o acesso a documentos escritos em diferentes suportes, através do acesso às novas tecnologias e a atividades de carácter cultural e educativo, permitindo " (...) um acesso livre e sem limites ao conhecimento, ao pensamento, à cultura e à informação " (p.2). Para que esta missão, diversificada e mobilizadora, possa ser cabalmente cumprida, as BPs precisam, quanto a nós, de dispor de SE bem planeados, programados, organizados e em funcionamento regular que Ihes permitam responder adequadamente às necessidades informacionais, educativas e culturais das comunidades envolventes. Só assim poderão atingir os principais objetivos que o mesmo Manifesto da UNESCO Ihes prescrevia, já em 1994.

Apesar disso, só 11 anos mais tarde se realizaram em Portugal, respetivamente em 2005 e 2006, o primeiro e o segundo Encontro de Serviços Educativos em Bibliotecas Públicas (http://mediadores-livros-e-leitores.blogspot.pt/2006/09/diferentes-leituras-ii-encontro.html), destinando-se a:

- Divulgar novas possibilidades na relação de prazer com a leitura.

- Difundir noções básicas sobre a compreensão leitora e a utilização de recursos técnico-expressivos.

- Aferir o emprego de novas tecnologias em serviço educativo e leitura especial.

- Apoiar a sedimentação de práticas educativas nas bibliotecas públicas. 
O II Encontro (2006) definiu como público-alvo, fundamentalmente: "profissionais e estudantes de unidades de informação e documentação, animadores, professores e educadores, dirigentes e técnicos de serviços e associações culturais"; contemplando assim um grande leque de destinatários, já que a promoção do livro é abrangente e pode ser fomentada em vários espaços e por vários profissionais. O que não supõe ignorar que o gosto da leitura deva começar na família, desde muito cedo!

Mas retomemos os objetivos desse último evento, detendo-nos em cada um mais pormenorizadamente.

Logo no primeiro: "Divulgar novas possibilidades na relação de prazer com a leitura", se enuncia uma meta que pode ser identificada e atingida nas sessões de leitura em voz alta, onde por exemplo na escola todos os dias um aluno lê para a turma uma frase ou mesmo um parágrafo de um livro, sendo que com esta atividade estamos a promover a leitura e a partilha de aprendizagens. A dramatização de histórias, os pequenos teatros que as crianças fazem, onde Ihes é dada a possibilidade de encarnar personagens e de viver novas emoções. O reconto e reinvenção de histórias é outra atividade que desenvolve a imaginação das crianças e mesmo dos adultos.

Já o segundo objetivo: Difundir noções básicas sobre a compreensão leitora e a utilização de recursos técnico-expressivos - remete-nos à competência leitora, ou capacidade de ler e interpretar a informação a qual é para Rigolet (1997, p. 25) “ um processo complicado que tem origem na simples descodificação grafofonémica e prossegue no seu aspecto mais abrangente de atribuição de um significado (...). Este sentido processa-se da sílaba até à palavra, da palavra à frase e depois ao texto na sua globalidade". É muito importante que o profissional de um serviço de biblioteca tenha conhecimentos relativamente a recursos expressivos utilizados na língua portuguesa, como é o exemplo da aliteração, a comparação, a enumeração e outros, porque desta forma mediante o público-alvo, pode recorrer a livros com mais ou menos recursos expressivos e desta forma promover a compreensão leitora. Também o trabalho com escolas, nomeadamente com os professores de português pode ser potenciado. Os serviços devem promover ações de formação no sentido transmitir estes conhecimentos aos profissionais, que não os possuam.

"Aferir o emprego de novas tecnologias em serviço educativo e leitura especial" foi o terceiro objetivo dessas jornadas. De facto, as TIC são hoje ferramentas imprescindíveis no dia-a-dia de trabalho e recreio dos cidadãos. A abundância de informação faz com que a sua utilização careça de saberes e cuidados especiais de seleção, domínio em que é importante que as BPs desenvolvam atividades específicas de pesquisa, seleção da documentação e informação diferenciadas em função da diversidade e igualdade dos utilizadores para promoção ampla da Literacia da Informação (LI). Essa amplitude do seu campo de ação e da atuação dos respetivos SE 
realçam, de forma prática e efetiva, o caráter universal e inclusivo das BPs já plasmado no Manifesto da UNESCO, onde os serviços "(...) devem ser oferecidos com base na igualdade de acesso para todos (...)" (1994, p.1). Decorre daí ainda o imperativo da leitura especial de modo que todos os utilizadores com e sem necessidades especiais sejam contemplados nas atividades e serviços das BPs.

Por último, e quanto ao objetivo de: "Apoiar a sedimentação de práticas educativas nas Bibliotecas Públicas”, é sabido que as BPs têm uma missão cultural, recreativa, educativa e informacional que prosseguem. Normalmente a missão educativa da biblioteca insere-se no âmbito da educação não formal, aquela que se aprende com os pais, com os amigos, nos jornais, no teatro... deixando a formal para a escola, a que segue programas rígidos e com objetivos concretos. Sendo que fica ao critério de cada biblioteca e de cada SE, dinamizar atividades que apoiem tanto a educação formal como a não formal, dependendo das necessidades dos utilizadores.

Podem depreender-se dessas linhas gerais para os SE em BPs enunciadas neste fórum nacional de discussão pública que enfatizou a função educativa da biblioteca pública, as principais preocupações sentidas pelas BPs - desde a promoção de livro e da leitura nas suas variadas formas e os aspetos formais da competência leitora, passando pelas novas tecnologias e literacias inerentes, até às necessidades próprias de públicos especiais.

Em síntese, este era nessa altura, o ponto da situação, ainda embrionário, dos Sistemas Educativos nas BPs portuguesas, na sua grande generalidade.

Impôs-se-nos então indagar dos avanços que posteriormente se foram verificando e conhecer de modo concreto e o mais exato possível, o desenvolvimento real e efetivo dos SE em BPs portuguesas nos últimos 8 anos, de 2006 a 2014, data de início do nosso trabalho de investigação empírica.

Para um diagnóstico mais preciso da situação a este nível, começamos por consultar, de uma forma aleatória, sites de 24 BPs (Fig.1), de forma a fazermos uma breve mas concreta incursão no tipo de atividades que estas bibliotecas oferecem aos seus utilizadores, no quadro e contexto dos SE. Esta foi aliás uma das etapas da revisão da literatura empreendida que nos permitiu avançar com mais segurança na investigação académica que nos propusemos depois desenvolver neste âmbito.

Numa primeira análise podemos identificar e estabelecer três grandes categorias de atividades: Promoção do Livro e da Leitura, Formação de Utilizadores, Educação e Cultura (Fig.2). Ressalvamos que as informações recolhidas apenas se confinam aos sites pesquisados em determinadas datas, nos período de (2 a 13 de agosto de 2013) e de (7 de dezembro a 7 de fevereiro de 2014). 
Figura 1 - Bibliotecas Públicas portuguesas com serviços educativos
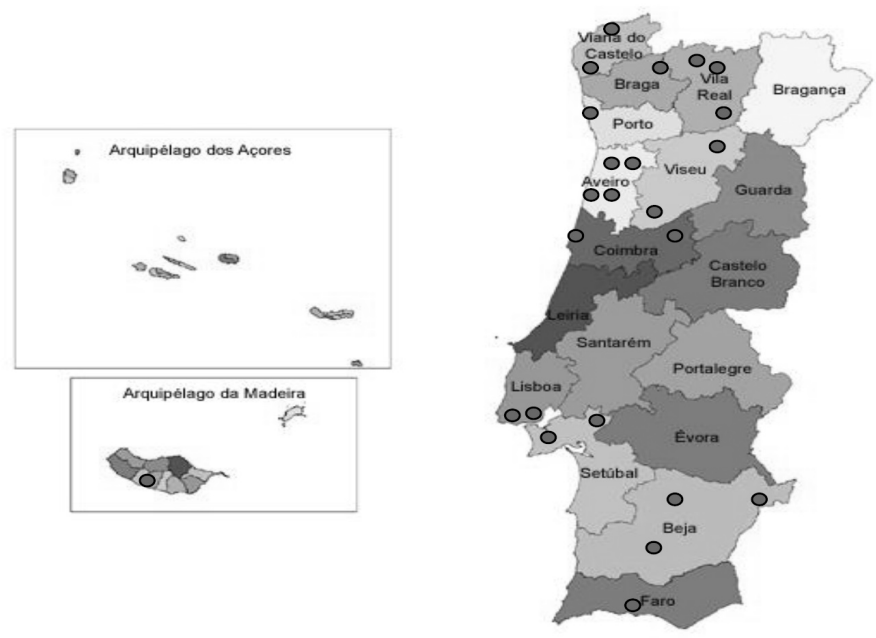

Fonte - sites das BPs

Figura 2 - Serviços educativos: principais grupos de atividades

\begin{tabular}{|c|c|c|c|}
\hline \multicolumn{4}{|c|}{ Serviços Educativos em Bibliotecas Públicas } \\
\hline Biblioteca & Promoção do livro e da leitura & Formação de Utilizadores & Educação / Cultura \\
\hline Póvoa do Varzim & 16 & 1 & 7 \\
\hline Ponte de Lima & 6 & 1 & 1 \\
\hline Cascais & 1 & 0 & 0 \\
\hline Ponta Delgada & 9 & 2 & 2 \\
\hline illhavo & 1 & 0 & 0 \\
\hline Albufeira & 2 & 3 & 1 \\
\hline Cantanhede & 3 & 0 & 2 \\
\hline Oliveira de Azeméis & 13 & 7 & 5 \\
\hline Mortágua & 7 & 1 & 4 \\
\hline Águeda & 7 & 1 & 3 \\
\hline Loulé & 3 & 1 & 1 \\
\hline Moura & 2 & 0 & 0 \\
\hline Aljó & 3 & 0 & 0 \\
\hline Aljustrel & 7 & 1 & 0 \\
\hline Seixal & 8 & 3 & 4 \\
\hline Oeiras & 3 & 0 & 1 \\
\hline Viana do Castelo & 3 & 0 & 0 \\
\hline Ribeira de Pena & 1 & 0 & 0 \\
\hline Vieira do Minho & 1 & 0 & 1 \\
\hline Penela & 1 & 0 & 0 \\
\hline Cuba & 0 & 0 & 1 \\
\hline Penalva do Castelo & 1 & 1 & 0 \\
\hline Montijo & 1 & 0 & 0 \\
\hline Aveiro & 1 & 1 & 0 \\
\hline Total & 100 & 23 & 33 \\
\hline
\end{tabular}

Fonte - Sites das bibliotecas pesquisadas (2013-2014) 
Analisando as diferentes atividades das BPs, publicitadas nos sites respetivos, podemos constatar que na área da promoção do livro e da leitura todas as bibliotecas apresentam atividades mesmo as que apenas restringem a sua ação a essa área como é o caso de Cascais, Ílhavo, Mortágua, Moura, Alijó, Penela, Ribeira de Pena e Viana do Castelo.

As bibliotecas que contemplam a formação de utilizadores são mais numerosas, destacando-se as de: Loulé, Aljustrel, Águeda, Mortágua, Oliveira de Azeméis, Albufeira, Póvoa do Varzim, Ponte de Lima, Aveiro, Penalva do Castelo, Seixal. A oferta contempla as visitas guiadas, elaboração de curriculum vitae, pesquisa no catálogo, formação na área da informática, nomeadamente para grupos séniores.

Relativamente à cultura e educação as bibliotecas visadas apresentam atividades relacionadas sobretudo com o fundo local e as exposições, para além do cinema, saúde e outras temáticas gerais de natureza cultural, registando-se no entanto um menor número de acções direcionadas para a dimensão da educação não formal.

As lógicas e estratégias dominantes evidenciadas nos SE nas BPs em Portugal, são ainda emergentes, ao que, pensa-se, poderão não ser alheios, os impactos diretos dos Encontros Nacionais realizados na primeira década de 2000

Mas daí a uma implantação, planificação e funcionamento generalizados de verdadeiros SE, nas BPs, à semelhança do que já hoje ocorre em grande parte dos museus portugueses vai ainda uma grande distância. Importaria pois diminuir esse fosso para que as BPs - cujo público-alvo abrange desde crianças e jovens em idade escolar até adultos e idosos cuja formação ao longo da vida deve ser incrementada - possam disponibilizar serviços de formação com qualidade e complementares da escola nas áreas da educação não formal e os quais não se esgotam nas categorias de atividades mais tradicionais e de caráter mais ou menos esporádico, identificadas na Figura 2.

Esta abordagem preliminar permitiu-nos assim a constituição desta primeira amostra, importante ponto de partida para o desenvolvimento de um estudo empírico sistematicamente realizado a nível nacional com um suporte metodológico assente na realização de entrevistas e na aplicação de um inquérito-questionário às 209 bibliotecas da Rede Nacional de Leitura Pública respondido por 103 bibliotecas numa percentagem de 49\%. Este estudo sistemático, com a avaliação e análise conceptual consistentes dos seus resultados, veio a revelar-se muito representativo do panorama nacional atual dos SE nas BPs da Rede de Leitura Pública. ${ }^{2}$

Tornou-se-nos então possível fazer a partir daí a caracterização mais abrangente, minuciosa e atualizada das atividades desenvolvidas já na década seguinte, nos SE das BPs pertencentes à Rede Nacional de Bibliotecas Públicas. A compilação e tratamento dos dados recolhidos com a aplicação extensiva do inquérito-questionário atrás referido permitiu-nos ainda, para uma outra amostra já mais significativa de 103 bibliotecas de todo o país, as seguintes conclusões: 
- A maior parte dessas BPs possui e disponibiliza SE.

- Na sua globalidade, a prática de organização e implementação de atividades coerentes e sistemáticas é uma realidade, embora registando um défice ao nível dos recursos humanos e financeiros.

- As linhas programáticas são, maioritariamente, da opção de cada biblioteca, o que revela autonomia mas ao mesmo tempo menor estruturação na ação e missão do SE das BPs.

- A não inclusão de um técnico superior em Educação, na equipa do SE é uma realidade expressiva a nível nacional, a mesma situação é constatada relativamente à inclusão de um profissional na área das bibliotecas e documentação.

- As atividades mais replicadas são as relacionadas com a promoção da leitura.

- A regularidade das atividades, na sua maioria, assenta na periodicidade semanal e maioritariamente para a faixa etária dos 7 aos 10 anos de idade.

- A participação das crianças nas atividades promovidas pelos SE é quase massiva.

- A intencionalidade ao nível da educação não formal revelou-se uma preocupação das BPs.

- O trabalho em parceria com as escolas, apesar de maioritariamente de caráter informal e ocasional, tem uma expressão muito positiva.

- A existência de bibliotecas sem SE, apesar da importância deste, é ainda muito expressiva.

Do nosso ponto de vista, a implantação e dinâmica generalizadas dos SE nas BPS exigem uma política de protocolos e parcerias a estabelecer com as escolas, agrupamentos escolares e bibliotecas escolares para planificação concertada de SE de qualidade e em complementaridade com as exigências do sistema educativo que importa estudar e pôr em prática, faseadamente.

Em tal contexto, é, por exemplo, fator preponderante o domínio das TIC cujo incremento nas BPs possibilitará a promoção de literacias informacionais e digitais e não apenas a tradicional promoção do livro e da literatura que no atual mundo digital se encontra em profunda mudança, designadamente, com o aparecimento da nova realidade - hipertexto. Trata-se de todo um conjunto de novos aspetos a considerar futuramente e que por isso se enunciarão adiante mais pormenorizadamente.

\section{Bibliotecas públicas e promoção da leitura}

As BPs são tradicionalmente identificadas com o livro e a leitura. Os livros constituem a oferta fundamental desta instituição, sendo reconhecida pelos cidadãos como espaços de difusão e preservação da cultura escrita. Daí que a promoção da leitura seja naturalmente assumida pelas BPs, com especial atenção junto das crianças e dos jovens (Hernández, 2010). 
Leal (2007, p.9) na mesma linha de Hernández refere "é nossa profunda convicção que a promoção da leitura deve ser assumida como a missão fundamental das bibliotecas públicas (...) ". E define leitura “ (...) como o processo de descodificação de um texto escrito num contexto significativo específico (para onde é convocada a história de vida de cada individuo leitor, ou seja as vivências, os afectos, os conhecimentos, as emoções, etc.) (...) " (obra acima citada, p.9). Ainda sobre a leitura e o contexto em que o indivíduo está inserido Freire (1992, p.119), considera que a leitura do mundo antecede a leitura da palavra, ora a compreensão do texto " (...) implica a percepção das relações entre o texto e o contexto".

Hernández (2010) refere que os hábitos de leitura tradicionais, devido às TIC, sofreram uma mudança em termos formais, de suporte mas não em conteúdo. Esta desconstrução do conceito clássico de leitura remete-nos para diferentes tipos de leituras e de leitores, facto que a promoção da leitura não pode descurar. Na promoção da leitura a dimensão lúdica (ler por prazer) e pragmática (ler para aprender) uma não pode ser sobrevalorizada em detrimento da outra. Nas atividades de divulgação da leitura nas bibliotecas a contemplação de vários tipos de leitores e de leituras, deve ser constante e sistemática.

\subsection{Leitura digital}

A forma como a leitura e a escrita se desenvolveram ao longo dos tempos esteve de acordo com os suportes e com os quadros sociológicos próprios de cada época.

Os suportes de escrita e leitura existiram sempre e com formas variadas: nos inícios eram as tabuinhas de argila, onde o texto ocupava a superfície; depois surgiu o rolo de papiro ou pergaminho, com o texto organizado em colunas; mais tarde com o códice aparece a delimitação da página e por fim a página branca do papel; atualmente o suporte privilegiado é a tela do computador (Soares, 2002) que Bolter (1991, p.5) designa de "Espaço de escrita".

Para Lévy (2000, p. 61) o hipertexto é “ (...) um texto móvel, caleidoscópico, que apresenta suas facetas, gira, dobra-se e desdobra-se à vontade frente ao leitor". Continuando, defende que o hipertexto é um princípio que não é novo, sendo a leitura de uma enciclopédia, de tipo hipertextual, com recurso a utensílios de orientação como: índices, sumários, dicionários, notas bibliográficas e outros.

Num outro estudo Levy (1994) refere que uma das maiores vantagens do hipertexto é a velocidade da reação ao clique do rato para chamar informação, que demora menos de um segundo. Mas alerta para a fácil desorientação ao trabalhar no hipertexto, que acontece mais facilmente do que no manuseamento de uma enciclopédia, isto porque a referência espacial e sensoriomotora que atua quando seguramos um volume desaparece no hipertexto. Borges (2002) concorda com Lévy, realça que esta passagem de uma geografia textual determinada para a liberdade da comunicação 
hipertextual, dinâmica e livre, onde as páginas não têm qualquer referência, onde impera a lógica de associação, constitui o principal trunfo e a principal fraqueza por levar à fácil desorientação do leitor.

Tanto o texto digital como o impresso são idênticos na mensagem, residindo a diferença na sua natureza.

Numa época em que a prioridade é dada à informação esta é mais acessível quando é transferida para meio digital. "Mas, o conceito de "informação" não é coincidente com o de "livro", este está muito além daquele". Para a autora os livros transportam conhecimento, sabedoria e imaginação, de narrativas que nos enriquecem e nos iluminam a realidade. Para muitos o livro representa uma forma de relacionamento humano com as coisas, determina uma forma de estar, uma fruição própria, que terá de reinventar-se ao passar para o formato digital (Borges, 2002, p.132).

Ora, muitas vozes se levantam e vaticinam o fim do livro em suporte papel. Somos de opinião que a informação e as TIC passarão por um crescimento avassalador num futuro próximo. Este cenário não irá destronar o livro. O computador deve ser visto como um facilitador.

\section{3 - Espaços educativos na Sociedade da Informação e do Conhecimento.}

Tem-se vindo a assistir no mundo contemporâneo a uma convergência cada vez mais estreita e de elevada premência social, entre os vastos e complexos domínios da educação e da informação tornados fulcrais no desenvolvimento técnico, tecnológico e cultural das sociedades e dos cidadãos.

Ora segundo Cabanas (2002, p.52) "o termo educação é como um poliedro de muitas faces", pluridimensionalidade. Já Castañé Casellas (1983) defende a necessidade de "saber com profundidade e exatidão o que é a educação [já que] implicaria não apenas defini-la segundo certos princípios essenciais como ver de que modo se realiza e é condicionada historicamente e como influencia a história num contexto sociocultural concreto" (p. 161).

Partindo dessa abrangência que a Educação supõe e se perfilha tornou-se-nos necessário tentar operacionalizá-la no quadro específico desta investigação o que se fez recorrendo a duas noções basilares e mais recentes que com ela se prendem diretamente: o da educação e ensino formal e o da educação não formal. A primeira caracteriza-se pelo seu carácter estruturante, tem lugar na escola. A segunda é veiculada pelos museus, bibliotecas, arquivos, associações, cursos livres, encontros com especialistas de várias áreas e outros espaços de encontro (Chagas, 1993).

Debruçando-se sobre a diferenciação destes espaços educativos, alguns estudiosos, como por exemplo Trindade e Cosme (2010) entendem ser a escola a representante do 
espaço formal e os restantes espaços em que destacamos a biblioteca, instâncias do espaço educativo não formal, esclarecendo no entanto que os mesmos não são equivalentes “ (...) quer do ponto de vista dos processos e das estratégias de influência educativa que aí têm lugar, quer finalmente, do ponto de vista das relações que aí se desenvolvem" (p.24). Defendem porém que as suas finalidades educativas devem ser as linhas condutoras, que num primeiro momento, contribuem para diferenciar a sua práxis. E explicitam no que diz respeito à educação formal que " (...) enquanto espaço educacional vocacionado para promover a apropriação de um dado património (...) [se encontra] circunscrito a um conjunto de opções curriculares prévias que constitui a sua principal finalidade, [concluindo] "Em suma, importa compreender que as experiências e vivências se subordinam, no caso das escolas, a aprendizagens e que estas, no caso dos contextos educativos não formais, não constituem uma prioridade intencional assumida (...) " (obra citada acima, p. 24).

A introdução desta sucinta reflexão justifica-se tanto mais quanto a Sociedade da Informação e do Conhecimento em que nos movemos gerou uma ampliação notável da premência de novas aprendizagens provocando a expansão dos contextos educativos para fora das fronteiras e limites da escola tradicional. Neste processo de profunda transformação de paradigmas da educação, comunicação e produção de conhecimentos, a informação tornou-se num dispositivo determinante e as bibliotecas, espaços educativos não formais, passaram a integrar na sua missão social cada vez mais funções educativas, sendo as experiências pessoais e sociais, assim como as experiências significativas e mobilizadoras que justificam a sua existência e importância na sociedade atual.

\section{Conclusão - Novos desafios para os SE das BPs e públicos-alvo}

As observações desenvolvidas e teoricamente enquadradas que se apresentaram em articulação integrada com os imperativos programáticos de ação cultural e missão educativa das bibliotecas atuais impele-nos a voltar os olhos para a emergência de um futuro próximo que se avizinha com maior premência no horizonte dos SE nas BPs.

A já corrente noção de born digital (nativos digitais) desenvolveu-se a partir de um conceito da autoria de Marc Prensky (2001) que apelida assim, a geração que nasceu a seguir ao aparecimento da Internet.

Como é dito por Silveira (2010, p. 145) “ (...) a Sociedade da Informação assenta na conjuntura de rede onde a escrita e a capacidade de compreender mensagens são os canais que permitem a circulação da comunicação, emerge a cabal importância do ato de ler." Continuando com mesma autora, saber ler e escrever desde sempre teve grande importância, aliás até chegarmos à democratização destas duas competências o caminho foi longo e sinuoso. Como atrás foi referido a leitura e, fundamentalmente a compreensão leitora, são essenciais para os nativos digitais, pelo que, atesta Silveira (p.152) "assim, não basta ter competências básicas de leitura, pois a incapacidade 
de descodificar, interpretar e compreender fará com que a Geração Net não consiga aceder, selecionar, compreender e produzir conhecimento (...)".

Esta nova geração apresenta lacunas ao nível da LI o que implica um reforço das competências leitoras. Um dos caminhos preconizados passa necessariamente pelos SE das BPs, e consiste em trabalhar com as crianças e os jovens a competência leitora através da utilização do livro e para uma melhor aproximação e motivação, utilizar o ambiente digital. E desta forma é preciso cumprir e saber agir, como Silveira (2010) adverte, nesse processo continuo em que a animação para a leitura é essencial para motivar e chamar a atenção para os conteúdos e mensagens do livro que devem ser alvo de reflexões e interpelações entre o mediador e o leitor, com recurso ao pensamento e à imaginação, forçar um contraciclo da leitura fragmentada, que se caracteriza por ser rápida.

Em sintese, o prognóstico precedente decorre naturalmente da matriz da nossa investigação centrada na análise intensiva dos SE das BPs a qual supõe um entendimento destas como instituições educativas de vasto espectro e longo alcance em sintonia com problemáticas e desafios dos novos paradigmas educacionais construtivistas em cujo estudo e conhecimento se tem de investir. Este preceito multifacetado tem na dimensão educativa e atividade informacional regular dos SE, campo de atuação principal das BPs, várias traduções de sentido complementar que apontam em duas direções essenciais: a) redefinição articulada de novos processos e estratégias, modernas formações e novas práticas no binómio interativo "educação não formal informação"; b) aquisição e ampliação de aptidões específicas no âmbito da complexa área cientifica da Educação pelos bibliotecários na sua função mais recente de educadores que os capacite na readaptação das suas tradicionais competências curriculares, sobretudo técnicas e, unilateralmente, direcionadas para uma processologia mais restrita das ciências da informação o que supõe continuar a investir no conhecimento e na investigação científica multidisciplinar.

Nota: Este artigo é o resultado de uma investigação para a Tese de Doutoramento em Educação, intitulada Serviços Educativos e Formação de Utilizadores em Bibliotecas Públicas e na Biblioteca Municipal de Gondomar: Um Estudo de Caso, apresentada e discutida em provas públicas no Instituto de Educação da Universidade Lusófona de Humanidade e Tecnologias.

\section{Notas}

1 A ainda escassa bibliografia especializada sobre os SE de Bibliotecas e em particular das Bibliotecas Públicas Portuguesas levou-nos a utilizar e citar sobretudo trabalhos e estudos sobre os SE em museus onde começaram por se desenvolver e se encontram já bastante mais e melhor documentados. Embora bibliotecas e museus sejam entidades culturais com particularidades e especificidades próprias, ambas partilham idênticas funções educativas procurando promover o enriquecimento e a valorização (in) formativa dos seus utilizadores.

2 Ver parte III da tese de doutoramento de Carla Bandeira. 


\section{Referências Bibliográficas}

Balça, A. \& Fonseca, M. A. (2012). Os docentes e a biblioteca escolar: uma relação necessária, Revista Lusófona de Educação, 20, 65-80. [Disponível em http://revistas.ulusofona.pt/index.php/ rleducacao/article/view/2938, consultado em Janeiro, 2016].

Barriga, S. (2011). Serviços educativos em Portugal: ponto da situação. Documento de recomendações. [Disponível em www.icomportugal.org/multimedia/CECA2011_SaraBarriga.pdf, consultado em Agosto, 2014].

Barriga, S. (2007). Plano de acção educativa: alguns contributos para a sua

elaboração. In S. Barriga \& S. Silva (Coord.), Serviços educativos na cultura (pp. 43- 55).Porto: Setepés.

Barriga, S. \& Silva, S. (2007). Serviços educativos na cultura: desenhar pontos de encontro. In S. Barriga \& S. Silva (Coord.), Serviços educativos na cultura (pp. 9-15). Porto: Setepés.

Bolter, J. (1991). Writing space: the computer, hypertext, and the history of writing. [Disponivel em http:// bit.ly/1cO24Gj, consultado em Setembro, 2014].

Borges, M. (2002). De Alexandria a Xanadu. Coimbra: Quarteto Editora.

Filipe, G. (2011). Diálogos, aprendizagens e educação nos museus: formulando

uma visão. [Disponível em http://www.icomportugal.org/multimedia/CECA2011_GracaFilipe.pdf, consultado em Setembro, 2014].

Freire, P. (1992). A importância do ato de ler. In P. Freire A importância do ato de ler: em três artigos que se completam (45. a ed., pp. 11 - 21). São Paulo: Cortez Editora.

Hernández, H. (2010). La lectura y la infromación en las bibliotecas públicas. In J.Calixto (Org.), Bibliotecas para a vida: literacia, conhecimento, cidadania (pp.43-50). Évora: Edições Colibri.

Leal, F. (2007). Introdução. In F. Leal (Coord.), Leitura (s) (pp. 9 - 16). Porto: Setepés.

Lévy, P. (2000). Cibercultura: relatório para o conselho da europa no quadro do projecto "Novas tecnologias: cooperação cultural e comunicação". Lisboa: Instituto Piaget.

Lévy, P. (1994). As tecnologias da inteligência: o futuro do pensamento na era da informática. Lisboa: Instituto Piaget.

Martins, M. (2003). O que é leitura. São Paulo: Brasiliense. [Disponível em http://www.ebah.pt/content/ ABAAAfcgOAA/que-leitura-maria-helenamartins, consultado em Setembro, 2014].

Neto, M. (2004). Do livro ao computador: o percurso labiríntico das palavras. [Disponível em http://www. ci.uc.pt/diglit/DigLitWebCdeCodiceeComputadorEnsaio09.html., consultado em Setembro, 2014].

Pescador, C. (2010). Tecnologias digitais e ações de aprendizagem dos nativos digitais. [Disponível em http://goo.gl/fbGyRZ, consultado em Agosto, 2014].

Prensky, S. (2001). Digital natives, digital immigrants. On the horizon, 9, 1-6. [Disponível em http://goo. gl/xXbX10, consultado em Agosto, 2014].

Rigolet, S. (1997). Leitura do mundo - leitura de livros: da estimulação precoce da linguagem escrita. Porto: Porto Editora.

Santaella, L. (2011). Os 3 tipos de leitores: contemplativo, movente e imersivo. 
[Disponível em http://designices.com/os-3-tipos-de-leitorescontemplativo-movente-e-imersivo/, consultado em Setembro, 2014].

Silveira, T. (2011). O impacto do contexto tecnológico no desenvolvimento da "arquitectura cerebral" para a leitura. [Disponível em http://bit.ly/1lyW3ZL, consultado em Agosto, 2014].

Silveira, T. (2010). Born digital: os novos leitores. In J. Calixto (Org.), Bibliotecas para a vida: literacia, conhecimento, cidadania (pp.145-162). Évora: Edições Colibri.

Soares, M. (2002). Novas práticas de leitura e escrita: letramento na cibercultura. Educação \& Sociedade, 23, 143 -160. [Disponível em http://www.scielo.br/pdf/es/v23n81/13935, consultado em Setembro, 2014].

UNESCO (1994). Manifesto da UNESCO sobre bibliotecas públicas. [Disponível em http://rcbp.dglb. pt/pt/ServProf/Documentacao/Documents/01_Manifesto_IFLA_Unesco_sobre_Bibliotecas_ Publicas_1994.pdf, consultado em Março, 2014].

Maria Otília Pereira Lage

Doutora em História Moderna e Contemporânea (U. Minho), Pós-doutorada em Novos Estudos Sociais e Históricos (U. Coimbra), Professora auxiliar convidada da Universidade Lusófona do Porto e Investigadora integrada do CITCEM (U. Porto). Email: otilialage@sapo.pt

Carla Bandeira

Doutora em Educação (U. Lusófona) Biblioteca Municipal de Gondomar. Email: bandeiracarla5@gmail.com

Correspondência Carla Bandeira Av. 25 de Abril, 164, $2^{\mathrm{a}}$ esquerdo. 4420 - 353 Gondomar

Data de submissão: Janeiro 2016

Data de avaliação: Março 2016 Data de publicação: Setembro 2017 